\title{
EPIPHYSEAL NECROSIS IN PITUITARY GIGANTISM
}

\author{
BY \\ ERICH TRAUB, M.D. \\ (From the Medical Department of the Children's Hospital, Brno, \\ Moravia [Director: Dr. Otto Saxl])
}

Drigalski and Diethelm (1937) recently described a case of gigantism, which showed degenerative changes in both hip joints. We have had an opportunity of observing a boy with similar symptoms, who is reported both on account of the rarity of these manifestations and in order to discuss the relation of the curious osseous changes to some bone diseases belonging to the group of epiphyseal necroses of bones (Aschoff. 1923). We hope to throw some light on the etiology of the above-mentioned disorder.

\section{Case report}

F. R., a boy aged six years, is the only child of healthy parents. The father and mother are of normal stature. According to the parents' statement, there are no known cases of abnormal height in the family. At birth the patient appeared to be unusually long, and his mother noticed the peculiar length of his toes. The child was exceedingly tall and broad when he began to walk at eighteen months of age. With the further development of the child, the parents noticed the rapid increase in size of his feet and especially of the toes, which frequently necessitated the purchase of new boots. The boy's growth greatly exceeded that of his contemporaries. For six weeks before admission to hospital the boy had complained of pains in his right hip and limped on the right leg. Walking was very painful. No other troubles were mentioned.

EXAMINATION on admission to the children's hospital at Brno on November 23, 1936, showed a tall boy of six years, who on account of his height looked considerably older (fig. 1). Height 53.9 inches $(137 \mathrm{~cm}$.) and weight $28.7 \mathrm{kgm}$. Average figures for his age, taken from Pirquet's and Kornfeld's examinations, are 45.2 inches $(115 \mathrm{~cm}$.) and $21 \mathrm{kgm}$. The shape of the head was mesencephalic. Innervation of the face was not abnormal. Mouth : mucous membranes and tonsils normal. Teeth well developed. Eyes : examination by Dr. Stein : on both sides the palpebral fissure was abnormally wide. Distribution of the scleral fields between temporal and nasal side is assymetric, which causes an apparent convergent strabismus. Both pupils are normally coloured, and surrounded by a ring of pigment. Vision 5/4. Range of vision normal.

The thyroid gland was not palpable. The internal organs showed nothing abnormal. The genitalia were well developed. Extremities : upper and lower extremities were extremely long, the length of the component parts being 
increased distally. The length of both arms was 22 inches $(56 \mathrm{~cm}$.). Arachnodactyly (fig. 2) was present. The interphalangeal joints were slightly thickened. The fingers could not be passively extended, suggesting Dupuytren's contracture. The length of legs was 28.7 inches $(73 \mathrm{~cm}$.) from the anterior superior iliac spine to the left internal malleolus (right) and 28.9 inches $(73.5 \mathrm{~cm}$.) (left). Genu valgum was present. First toes were extremely long, the big toe on both sides measuring 2.3 inches $(6 \mathrm{~cm}$.), second toe 1.5 inches $(4 \mathrm{~cm}$.), third, fourth, and fifth toes $1 \cdot 3$ inches $(3 \cdot 5 \mathrm{~cm}$.) (fig. 3).

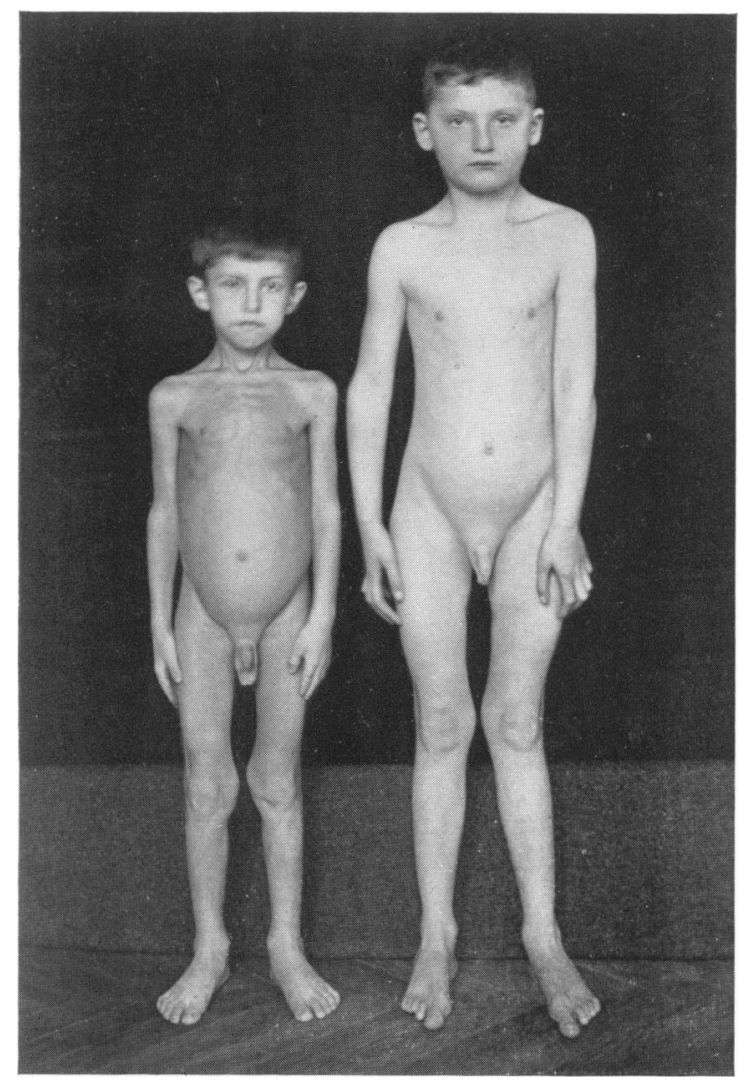

FIG. 1.-The patient (right) besides a boy, aged six years of normal size (left).

The temperature remained normal throughout. The red blood cells numbered 5,200,000 per c.mm. and the haemoglobin content (Sahli) was 94.4 per cent. The white blood cells numbered 9,$900 ; 2$ per cent. were eosinophils, 1 per cent. were young forms, 2 per cent. were band forms, 58 per cent. were segmented, 30 per cent. were lymphocytes, 7 per cent. were monocytes. The sedimentation rate was three hours by Linzenmeire's microsedimeter. The urine was normal. The intracutaneous tuberculin test (Mantoux, $1 \mathrm{mgm}$.) gave a negative result. The basal metabolism was 51 per cent. below normal. Specific dynamic effect of proteins was after 60 minutes : 38.22 per cent., after 90 minutes : $79 \cdot 21$ per cent. (normally $20-40$ per cent.) ; therefore 30 per cent. raised. The urine concentration was normal. The serum calcium content was 
found to be $13 \mathrm{mgm}$. per 100 c.c. The blood sugar curve after oral administration of 50 grammes glucose was of normal type. Fasting blood sugar was

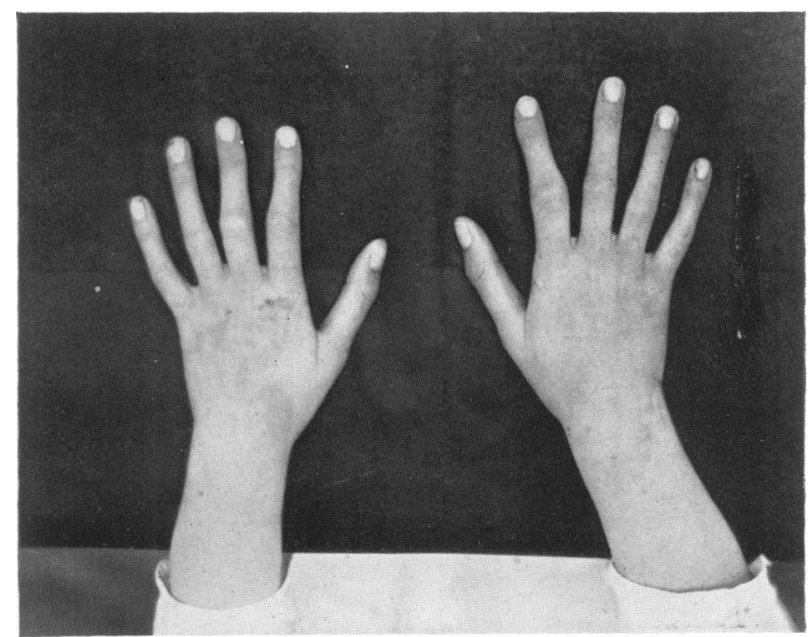

FIG. 2.-The hands show arachnodactyly. The deflected position of the fingers resembles Dupuytren's contracture.

$100 \mathrm{mgm}$. per cent. After a quarter of an hour the blood sugar was $150 \mathrm{mgm}$. per 100 c.c., after half an hour it rose to $160 \mathrm{mgm}$. per 100 c.c., after an hour and a half the blood sugar fell to $75 \mathrm{mgm}$. per 100 c.c., after three hours and a

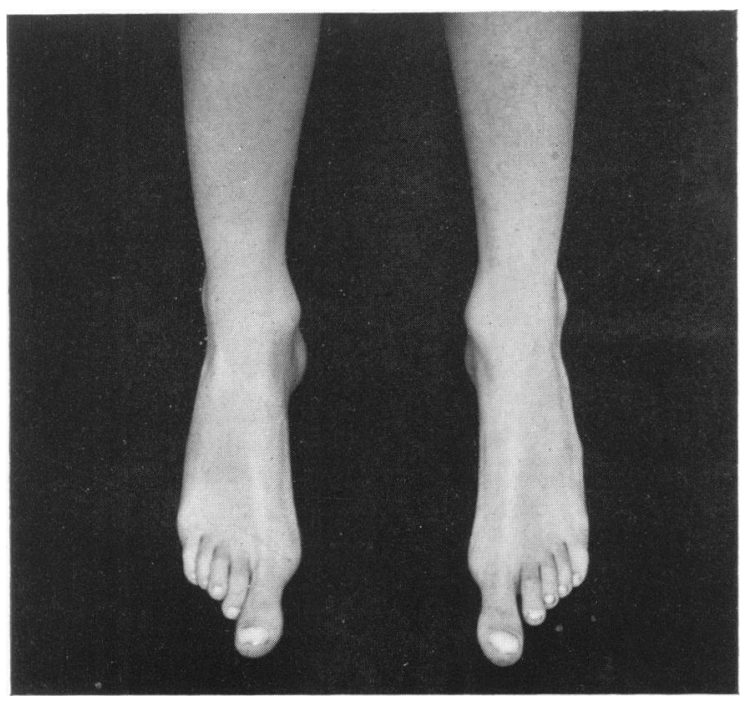

FIG. 3.-Photograph of the feet. First toes are extremely long.

half it regained its normal value of $100 \mathrm{mgm}$. per 100 c.c. (Crecelius-Seifert colorimetric method of determination).

The boy was apparently intelligent. 
RADIOLOGICAL REPORTS (November 23, 1936) :

Hands : show arachnodactyly.

Feet (fig. 4) : 1. Navicular of tarsus on each side : The centre of ossification of the navicular is broken into several fragments the size of lentils. The particles have a heterogeneous structure and at some places the structure shows increased density.

2. First metatarsal on each side : The head of the first metatarsal is flattened, as though compressed, a little withdrawn and broken up into several fragments.

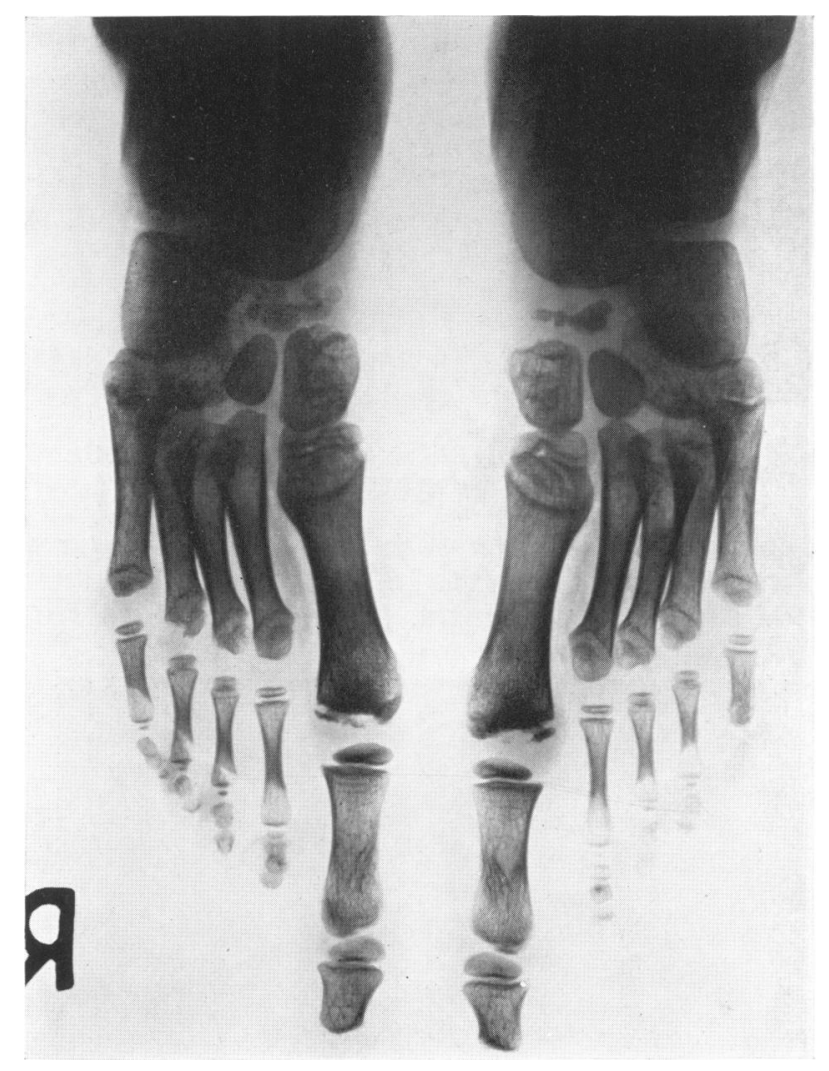

FIG. 4.-X-ray of feet (November 23, 1936). 1. Bilateral tarsal scaphoids are fragmented into pieces of irregular structure with areas of increased density. 2. The heads of first metatarsals are flattened and show some deep defects. The articular space is visibly and assymetrically enlarged.

The bone structure is in some places condensed. The articular space is visibly and assymetrically enlarged, the fibular side more than the tibial one.

Skull : No signs of increased intracranial pressure. The sella is normal.

Right hip joint : The right femoral head is flattened and shows irregularity of structure. The whole head is displaced, so that its cranial margin approaches the trochanter. The capital epiphysis shows a mottled appearance (peau de léopard). The neck is widened and shortened. The articular space is irregularly enlarged. The right acetabulum is flatter than on the left and shows an irregular outline (fig. 5). 
Bodies of vertebrae (fig. 6): The structure shows increased density (eburnization).

Progress : On December 8, 1936, the right hip was fixed in plaster and on December 12, the patient was discharged. On account of the low basal metabolic rate, treatment with thyroid tablets was started. As the patient complained of being 'pinched,' the plaster was removed on January 21, 1937. On March 21, 1937, the patient was sent to the children's hospital at Brno for re-examination. The height of the child was 54.7 inches $(139 \mathrm{~cm}$.), the weight was $31.6 \mathrm{kgm}$. X-rays taken of his hips showed the following changes: The flattening and destruction of the capital epiphysis of the right femur was pro-

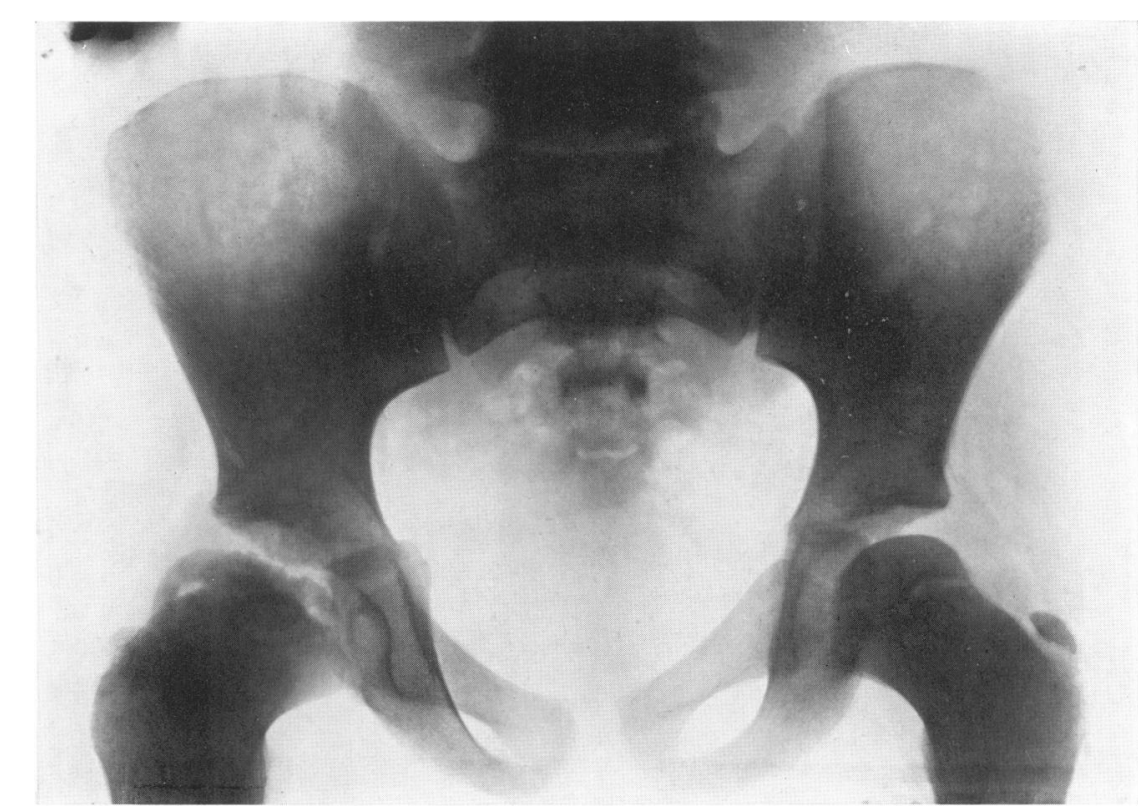

FIG. 5.-X-ray of hip joints (November 23, 1936). The right femoral head is flattened and displaced, so that its cranial margin approaches the trochanter. The epiphyseal plate shows a mottled appearance. The neck is shortened and widened.

gressing. The cranial margin of the head had reached the trochanter. X-rays of the feet : 1 . The fragments of the ossification centres of both tarsal scaphoids had become larger. The disturbed relation between bone and cartilage seemed to have altered in favour of the bone. 2. Heads of the first metatarsals : The bony fragments had become larger. The flattening of the articular surface was decreasing. The articular space had become smalier (fig. 7).

A third examination of the boy in June 1937 showed a height of 55.5 inches $(141 \mathrm{~cm}$.). The patient visibly limped and complained of pains in the right hip joint.

An x-ray examination on November 22, 1937, showed in the right hip joint that the regressive process of the right femoral head was little changed. Feet : 1. The ossification of the navicular was progressing. The size of the scaphoid could distinctly be seen. 2. Head of the first metatarsal : Healing of the distal epiphysis was proceeding.

On June 17, 1938, a further examination of the boy (now aged eight years) showed his height to be 57.8 inches $(147 \mathrm{~cm}$.). The average figure for his age, 
taken from Pirquet's and Kornfeld's estimations, is 50 inches $(127 \mathrm{~cm}$.). The length of bones: Anterior superior iliac spine to internal malleolus was 30.7 inches $(78 \mathrm{~cm}$.) on both sides. The length of the feet was 9.4 inches $(24 \mathrm{~cm}$.) (right) and $9 \cdot 8$ inches $(25 \mathrm{~cm}$.) (left).

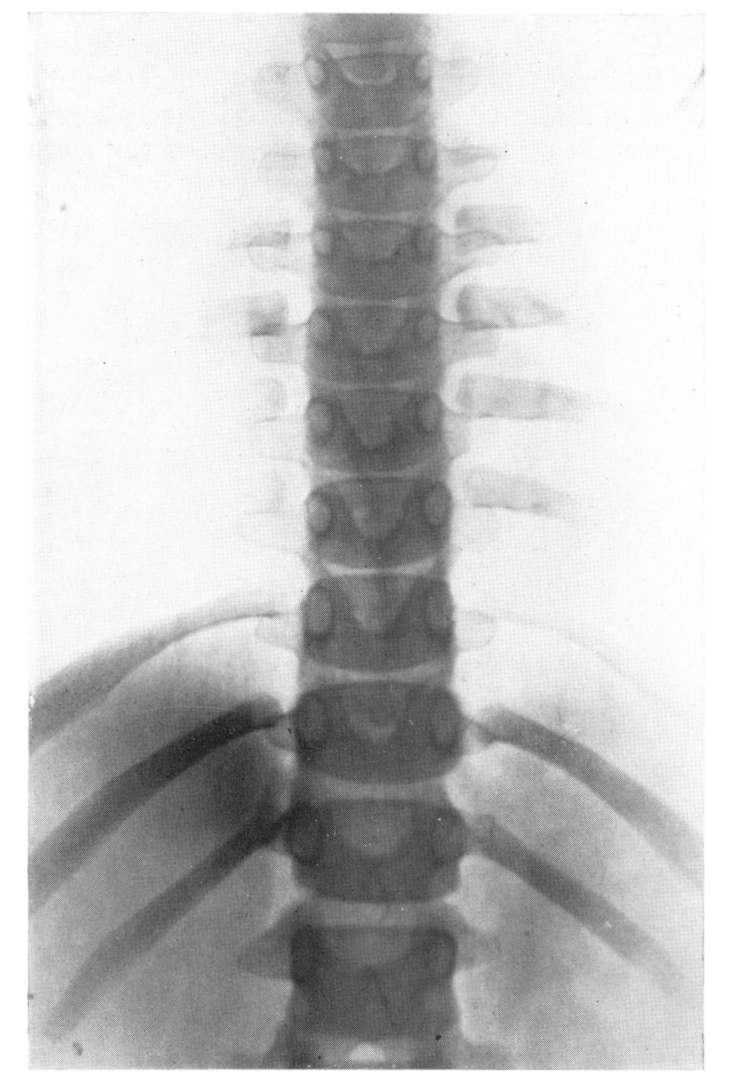

FIG. 6.-X-ray of vertebrae (November 23, 1936). Bodies of the vertebrae show increased density (eburnization).

RADIOLOGICAL REPORT :

Hip joints : The head, epiphysis and neck of the right femur were joined in a single mottled mass (fig. 8).

Feet : 1. The tarsal scaphoids showed irregularity of structure and increased density. The size and volume of the bone had become approximately normal.

2. First metatarsals : The heads of the metatarsals had regained normal size. In place of the former osseous fragments the bone was more calcified. The width of the articular space had become normal (fig. 9).

Bodies of vertebrae : The density of structure had become normal (fig. 10).

SUMmaRY.-This is the case of a boy with pituitary gigantism. The low basal metabolic rate indicates a simultaneous deficiency of the function of the thyroid gland. A connexion between elevation of specific dynamic actions of protein (such as was observed in this case) and dysfunction of the pituitary body was formerly supposed, but has recently been questioned (Nobel, 1937). The patient exhibited arachnodactyly of the hands and feet. It has repeatedly 


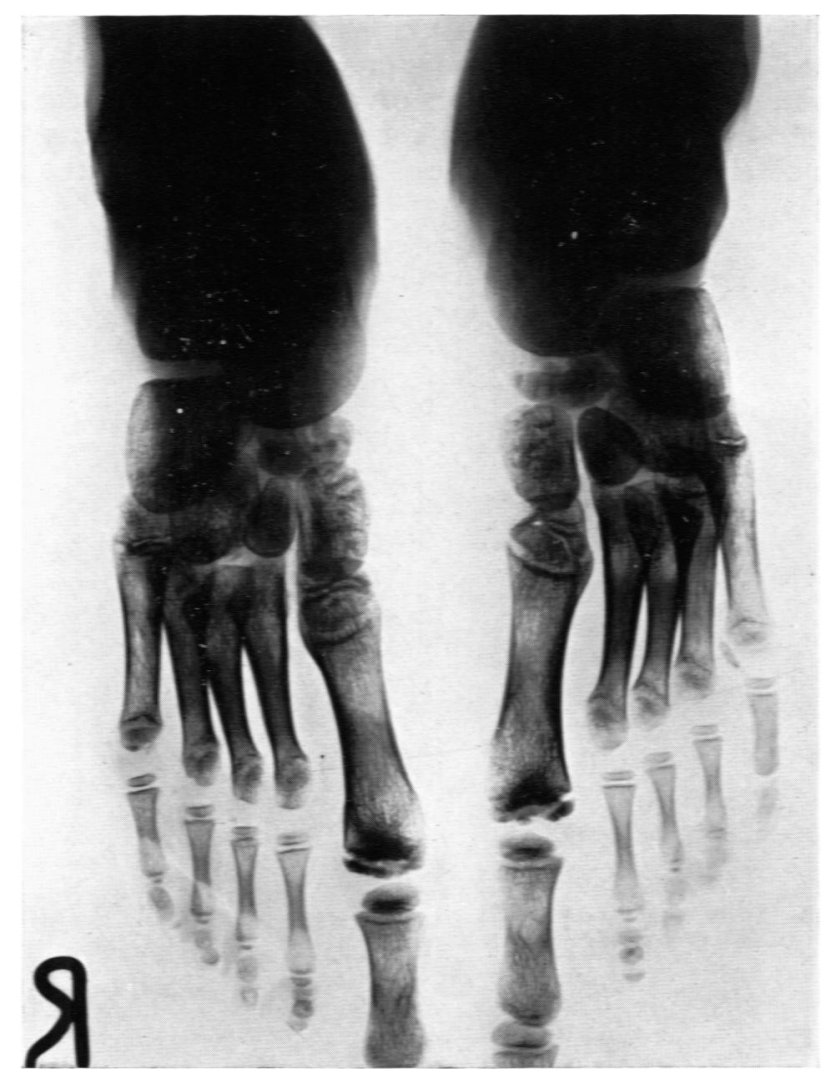

IG. 7.-Feet. X-ray of feet (March 21, 1937). 1. The fragments of the centres of ossification of both tarsal scaphoids have become larger. 2. Heads of first metatarsals : The flattening of the joint plane is decreasing. The articular space has become smaller.

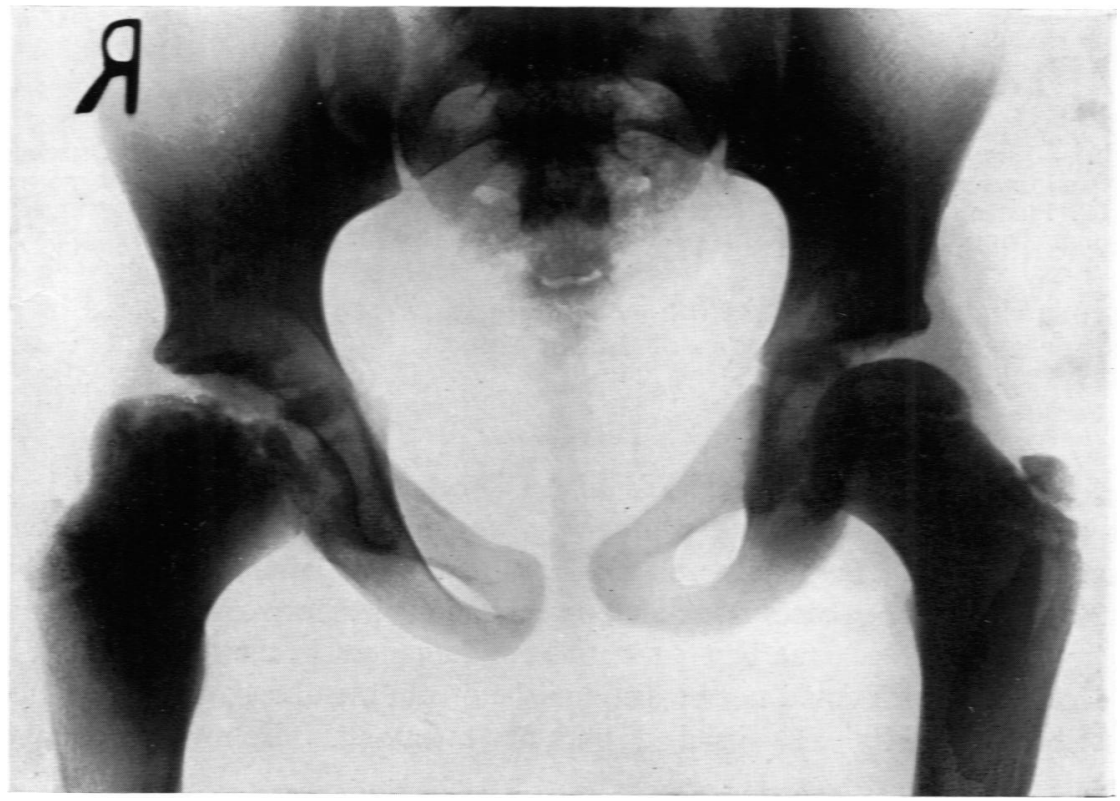

Fig. 8.-X-ray of hip joints (June 17, 1938). The right femoral head and neck are joined into a single mottled mass. 
been suggested that arachnodactyly is associated with disturbance of the ductless glands. A deflected position of the fingers, as in the case of this patient, which resembled Dupuytren's contractures, has been observed in several cases of arachnodactyly. The x-ray examination of the boy revealed

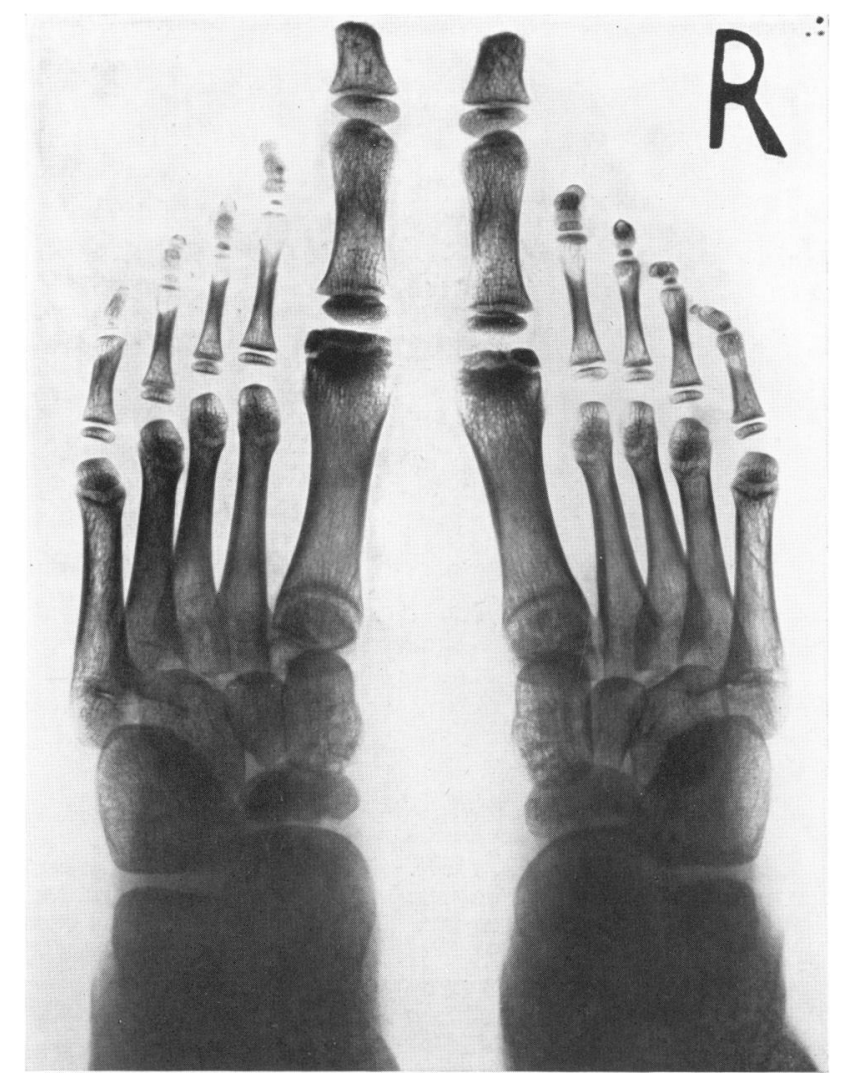

FIG. 9.-X-ray of feet (June 17, 1938). 1. The tarsal scaphoids show irregularity of structure and increased density. The size of these bones has almost returned to normal. 2. First metatarsals: The heads are now of normal size and the irregular appearance has changed to more uniform ossification. The width of the articular space is normal.

osseous changes of the right hip joint, both tarsal scaphoids, the head of the first metatarsals and the bodies of the vertebrae.

\section{Discussion}

This case resembles Drigalski's and Diethelm's (1937) observation in so far as both patients showed pituitary gigantism accompanied by regressive osseous changes. Besides the disturbances of the hip joints, which according to the X-rays in both cases resembled osteochondritis deformans coxae juvenilis (Legg-Calvé-Perthes), the first patient showed changes in the tarsal scaphoids of each side, which could not be distinguished from the disease of the navicular described by Köhler. The heads of both first metatarsals also revealed changes, 
like those which Köhler and Freiberg described in the heads of the second and third metatarsals. We have not found any report of a similar disorder of the first metatarsal in the literature. Finally there was eburnization of the bodies of the vertebrae.

There is the question if in the present and Drigalski's and Diethelm's (1937) cases the disorder of the hip joint could be interpreted as genuine Perthes' disease, and the changes in the tarsal scaphoids as Köhler's disease. Drigalski and Diethelm (1937) emphasize the fact that regressive osseous changes of the hip joint appearing in children with gigantism, and genuine osteochondritis

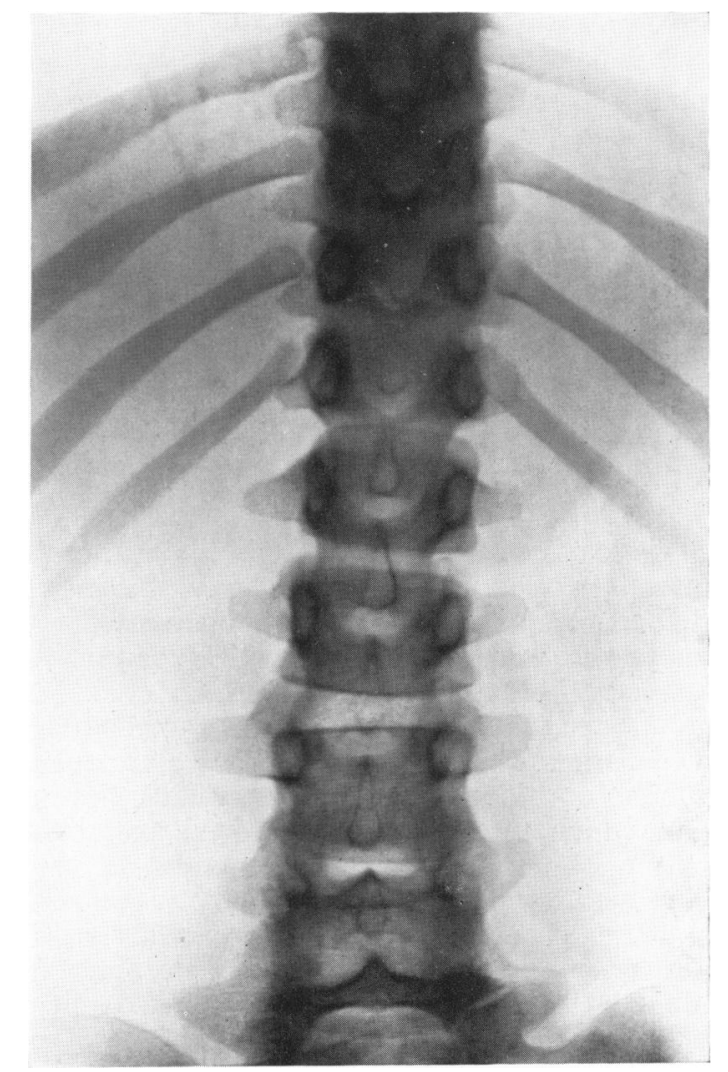

FIG. 10.-X-rays of vertebrae (June 17, 1938). Eburnization has disappeared.

deformans coxæ must be strictly distinguished. The authors compare the above-mentioned changes in the bones accompanying gigantism with skeletal disorders in acromegaly, which, like gigantism, is caused by over-secretion of pituitary growth hormone. Brissaud (1931) and Erdheim (1930) conclude that the manifestation of gigantism or acromegaly depends on the age of the individual, and thus on the maturity of the epiphysis. If the excessive growth hormone meets open epiphyseal lines, it causes an increase of growth. Once endochondral ossification is completed, the growth hormone can no longer act in these areas. Regressive changes in bones and joints in acromegaly were described by Curschmann (1905), Fraenkel, Stadelmann and Benda (1901), 
Dietrich (1909), Salus (1933), Steiger (1917), and Erdheim (1930). With these disorders Drigalski and Diethelm (1937) compare the changes in the head of the femur and vertebrae in their over-grown boy. They repeatedly emphasize that the condition observed by them only resembles Perthes' disease, though allowing that $\mathrm{x}$-ray appearances similar to osteochondritis may be caused by different etiological factors. However, these authors wish to distinguish the osseous changes observed by them from genuine Perthes' disease.

It is assumed that regressive osseous changes in the hip joint accompanying gigantism cannot be convincingly distinguished from the condition generally known as osteochondritis deformans coxae juvenilis (Legg-Calvé-Perthes' disease). The x-rays of the present case show fragmentation of the right femoral head, which is flattened and displaced in the direction to the trochanter. The epiphyseal plate shows a mottled structure. The neck of the femur is thickened and shortened. The articular space appears wide. All these signs definitely resemble Perthes' (1924) classical description of x-rays of osteochondritis deformans. Several reports of Perthes-like osseous changes accompanying endocrine disturbances have appeared in the literature. Thus Erkes (1921), Riedel (1922), and Drehmann (1914) described cases of osteochondritis coxae occurring in adiposogenital dystrophy, Brandes (1920), Kostlivý (1922), and Roth (1918) mentioned Perthes' disease in hyperthyroidism, Benjamin and Miller (1938) in hypothyroidism, Läwen (1909) in cretinism, Dorner (1921) in pituitary dwarfism, Schmidt (1927) in gigantism.

The question if these osseous changes in the hip joints occurring in gigantism, such as are observed in the present case, should be interpreted as typical osteochondritis deformans coxae juvenilis, or as a bone disease sui generis, or as arthritis deformans acromegalica (Erdheim, 1930) can only be answered by a clear definition of the pathology of Perthes' disease.

It should be mentioned that there is no general agreement as to the pathology of osteochondritis deformans coxae juvenilis. There are authors such as Calot and Colleu (1922) who consider that the primary fault lies in maldevelopment of the acetabulum, which resembles the flattened acetabular cavity seen in congenital dislocation of the hip. The deformation of the femoral head is supposed to be a secondary change. In the same way Preiser (1907) regards the displacement of the articular surfaces accompanying malformations of the acetabulum as being responsible for the occurrence of osteochondritis. According to Köhler (1924) the disturbance of static unity in the hip joint (the dysarthria of Bibergeil [1912]) is the reason for development of Perthes' disease, after bloodless reduction of congenital dislocation of the hip, after which a subluxation of the head of the femura often remains. The assumption that the trauma of reduction might be the reason for the epiphyseal necrosis is considered by Obadalek (personal communication) (chief of the orthopedic department of the children's hospital at Brno) to be contraindicated by the fact that changes in the head of the femur do not usually follow the reduction, but occur when the hip joint has to bear the weight of the body in walking and the disturbance of static unity comes into play. To these attempts to explain osteochondritis by functional activity, Perthes (1924) opposes the objection that the epiphyseal necrosis often occurs on the healthy side, and not in the hip in congenital dislocation. According to this author the displacement of the articular surfaces is not the cause, but the result of osteochondritis.

Perthes therefore agrees with the authors who consider the chief reason for 
the occurrence of osteochondritis deformans coxae is an inherited disturbance of growth and ossification, occurring in the epiphysis of the head of the femur (Weil, 1921; Zaaijer, 1921 ; Fromme, 1920; Eden, 1912; Liek, 1922 ; and others). According to Perthes the inherited condition causes a loosening of the epiphyseal plate, due to which minor trauma may cause a laceration of blood vessels. As a result of these processes the typical changes of epiphyseal line may occur. Several authors consider that the disturbance of ossification may have a congenital basis, which is perhaps supported by the occurrence of hereditary cases of osteochondritis (Zaaijer, Weil, Perthes, Fromme and others). Another group of authors regard the underlying disorder as an endocrine disturbance (Liek, Sorrel, Benjamin-Miller, Sundt, Erkes, Läwen, Brandes and others). On this assumption of an endocrine cause of the osteochondritis, it is probable that abnormalities of osseous development would appear not only in the epiphysis of the femur, but also in other centres of ossification.

In any case, many authors regard the osteochondritis deformans coxae as part of a general skeletal disorder. There have been many reports on osseous changes occurring simultaneously with Perthes' disease. Fromme (1920) emphasizes that the osteochondritis is not a local disorder, but a symptom of a general disturbance of the endochondral ossification, and may therefore appear in each epiphysis. He mentions similar changes in the head of the second metatarsal. Since this note was published several cases have been recorded of osteochondritis coxae, occurring simultaneously with maldevelopment of other parts of the skeleton. Thus Weil observed absence of multangulum majus and minus. Perthes mentions large trochanters in several cases of osteochondritis coxae. Köhler describes two cases in which necroses of tarsal scaphoid (Köhler's disease) co-existed with osteochondritis coxae.

Similarly, in the case of the present patient, who was suffering from osteochondritis deformans of the right hip, the x-rays showed bilateral Köhler's disease of the navicular of the tarsus. Köhler considers that the co-existence of such disorders is much more frequent than the reports in the literature suggest. In only two out of a hundred cases of Köhler's disease, which Köhler found in the literature up to 1923, had the hips been examined. Otherwise, according to Köhler, this combination would be found more frequently.

Köhler's assumption seems probable. Like Fromme many authors have accepted his conception. In the same way, as Köhler, Freiberg and Fromme described analogous changes on the head of the second metatarsal, other reports have been published of changes in the tarsal scaphoid (Köhler's disease), Osgood-Schlatter's disease of the tibial tubercle, necrosis of lunatum (Kienböck's disease) and osteochondritis ischiopubica (first described by Van Neck, 1924), recently observed by Corper (1938). These osseous changes in different situations have been classified by several authors ; Zaaijer (1921) uses the term osteochondropathia juvenilis parosteogenetica; Ombrédanne (1925) : dyschondroplasia ; Weil : dysplastic malacies ; Aschoff : epiphyseal bone necroses. In this paper we have adopted Aschoff's nomenclature.

We consider that the same disturbance of ossification and growth as is caused by endogenous factors may be responsible for all the above-mentioned osseous changes. According to Weil all these disorders have a common characteristic, namely a displacement of the proportion between bone and cartilage in favour of the cartilage. Several symptoms are considered to be characteristic of all the conditions : The x-rays are similar, the disorder occurs mostly in boys, it appears during adolescence, it has a benign course, usually ending with complete recovery. In addition to the cases described by Weil, Perthes, Köhler, there is a report by Köhler of the association of Köhler's navicular disease with maldevelopment of the patella, whilst Sonntag (1922) 
published a description of a child with Köhler's navicular disease, who showed a disturbance of the lower femoral epiphysis. Caan (1924) quotes Behn and Grashey who observed Köhler's disease associated with delayed carpal development, and Mandl's report of simultaneous appearance of Osgood-Schlatter's disease, slipped epiphysis of the trochanter, olecranon, calcaneus and tuberosity of the fifth metatarsal.

The present patient showed an unusual association of epiphyseal necroses. Besides a typical osteochondritis deformans of the right hip joint, there was Köhler's disease of both tarsal scaphoids. The spontaneous healing of the navicular disorder is significant ; this feature is, according to Perthes, characteristic of the epiphysial necroses. The vertebral bodies showed eburnation. As a particular condition maybe mentioned the changes in the distal epiphyses of the first metatarsals. The peculiar $\mathrm{x}$-ray appearance previously described in this case corresponds to the regressive osseous changes described by Köhler in the head of second and third metatarsals. The only difference in the present case was the absence of widening of the distal end of the metatarsal, which feature Köhler emphasizes, although he admits that there may be rare exceptions. Köhler doubts if Köhler-Freiberg's disease can occur in the first metatarsal. He maintains that all similar x-rays which he has seen have been examples of chronic arthritis. However, in the present case chronic arthritis can definitely be excluded, since not only are the articular spaces usually decreased in arthritis, but also the clinical course of arthritis is progressive, while in this case the cartilage of the metatarsal head showed an obvious tendency to heal. It is therefore concluded that the osseous changes in the head of the first metatarsal are subchondral necroses and classify this disorder in the group of epiphysial necroses, which, as already mentioned, may occur in all parts of the skeleton. We have not found any report of epiphyseal necrosis of the first metatarsal in the literature.

The occurrence of multiple epiphyseal necroses in this case furnish strong evidence of disease affecting the entire skeletal system. It seems probable that this systemic disorder should be attributed to the endocrine disorder with which the patient was affected. Reliable authors, such as Köhler, Perthes, Zaaijer and others, maintain that the epiphyseal necroses must be caused by a disorder of the entire skeletal system. There are various opinions, however, as to the nature of the endogenous factor. Weil and Zaaijer believe that a congenital disturbance of development is responsible ; Fromme supposes late rickets ; Liek and others regard the cause as an endocrine disorder. In the present case the overgrowth might have caused a defect of the excessive cartilage and bony tissue produced. The view has already been mentioned that mechanical disturbances of the function of the hip joint may be responsible for the appearance of the osteochondritis deformans coxae. Similarly Köhler regards the abnormality of the tarsal scaphoid as due to the late ossification of the navicular of the tarsus, its defective blood supply, and the pressure exerted on it by the adjacent bones of the tarsus. The changes in the heads of the second and third metatarsals may, according to Köhler, be attributed to mechanical factors. He quotes Beely's observation that the foot chiefly rests upon the heel and the heads of second and third metatarsals, just the places where epiphyseal necroses are usually localized. It appears possible that in the present case the disorder of the tarsal scaphoid and the extreme length of the toes might have caused a displacement of the centre of gravity of the foot, so that the load 
would fall not on the second and third but on the first metatarsophalangeal joint. This hypothesis might explain the appearance of regressive osseous changes in this unusual situation. The exceptional height of the patient may have caused a general disturbance of static proportions, resulting in the multiple epiphysial necroses.

\section{Summary}

A case is reported showing multiple epiphyseal necroses, in which the whole skeletal system appeared to be affected. X-ray examination showed a typical osteochondritis deformans of the right hip joint : Köhler's disease of both tarsal scaphoids; changes in the bodies of the vertebrae; and epiphyseal necrosis in the heads of the first metatarsals, a condition which does not appear to have been reported previously. In many cases of epiphyseal necrosis nothing is known regarding the etiology of the osseous changes. In the case here reported, the skeletal changes appear to have been caused by endocrine dysfunction.

Dr. Karl Mendl, radiologist of the children's hospital at Brno, gave assistance and constructive criticism.

\section{REFERENCES}

Aschoff, L. (1923). Münch. med. Wschr., 68, 650.

Benjamin, B., and Miller, P. R. (1938). Amer. J. Dis. Child., 55, 1189.

Bibergeil, E. (1912). Z. orthop. Chir., 30, 163.

Brandes (1920). Med. Klin., 16, 245.

Brissaud, see Beumer, H.(1931) in Pfaundler-Schlossmann's Handbuch der Kinderheilkunde, 1, 1064.

Caan, P. (1924). Ergebn. Chir. Orthop., 17, 64.

Calot, F., and Colleu, H. (1922). Presse. méd., 30, 35.

Corper, F. J. (1938). Amer. J. Dis. Child., 56, 957.

Curschmann, H. (1905). Fortschr. Röntgenstr., 9, 83.

Dietrich, A. (1909). Verh. dtsch. path. Ges., 13, 78.

Dorner, G. (1921). Münch. med. Wschr., 68, 287.

Drehmann, G. (1914). Beitr. klin. Chir., 91, 642.

Drigalski, W., and Diethelm, L. (1937). Klin. Wschr., 16, 628.

Eden, R. (1912). Dtsch. Z. Chir., 117, 148.

Erdheim, J. (1930). Virchows Arch., 281, 197.

Erkes (1921). Zbl. Chir., 48, 775.

Fraenkel, A., Stadelmann, E., and Benda, C. (1901). Dtsch. med. Wschr., 27, 513, 536, 564.

Fromme, A. (1920). Beitr. klin. Chir., 118, 493.

Köhler, A. (1924). Die Grenzen des Normalen und Anfänge des Pathologischen im Röntgenbild Leipzig, 4th edition, 77, 94, 154.

Kostlivý, S. (1922). Bratislavské lekárs. List., 1, 4.

Läwen, A. (1909). Dtsch. Z. Chir., 101, 454.

Liek, E. (1922). Arch. klin. Chir. 119, 329.

Nobel, E. et al. (1937). Innere Sekretion und Konstitution im Kindesalter, Vienna, 32.

Ombrédanne, L. (1925). Précis clinique et opératoire de chirurgie infantile, Paris, 916.

Perthes, G. (1924). Klin. Wschr., 3, 513.

Preiser, G. (1907). Dtsch. Z. Chir., 89, 613.

Riedel, G. (1922). Münch. med. Wschr., 69, 1529. 
Roth, L. (1918). Korresp. Bl. schweiz. Arz., 48, 951.

Salus, F. (1933). Z. ges. Neurol. Psychiat., 148, 577.

Schmidt, A. (1927). Z. orthop. Chir., 48, 229.

Sonntag, L. (1922). Münch. med. Wschr., 69, 1567.

Sorrel, E. (1922). Rev. Orthoped., 9, 637.

Steiger, L. (1917). Z Z. klin. Med., 84, 291.

Sundt, H. (1921). Med. Rev., 38, 145.

Van Neck, M. (1924). Arch. franco-belg. Chir., 27, 238.

Weil, S. (1921). Beitr. klin. Chir., 122, 418.

Zaaijer, J. H. (1921). Dtsch. Z. Chir., 163, 229. 